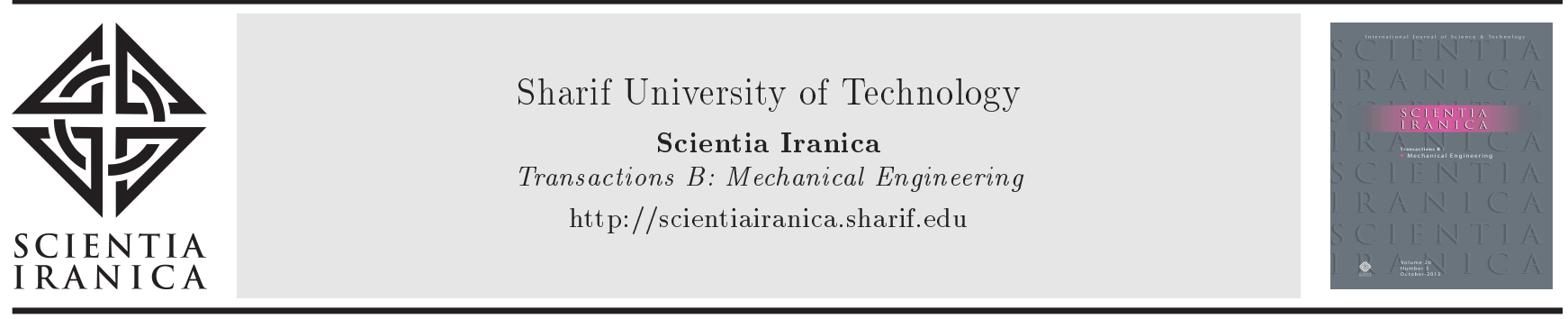

\title{
Effects of in-situ formed TiB whiskers on microstructure and mechanical properties of spark plasma sintered $\mathrm{Ti}-\mathrm{B}_{4} \mathrm{C}$ and $\mathrm{Ti}-\mathrm{TiB}_{2}$ composites
}

\author{
A. Sabahi Namini ${ }^{a, *}$, M. Azadbeh ${ }^{a}$, and M. Shahedi Asl ${ }^{\text {b,* }}$ \\ a. Department of Materials Engineering, Sahand University of Technology, Tabriz, Iran. \\ b. Department of Mechanical Engineering, University of Mohaghegh Ardabili, Ardabil, Iran. \\ Received 24 August 2016; received in revised form 13 November 2016; accepted 8 April 2017
}

\author{
KEYWORDS \\ Spark plasma \\ sintering; \\ Titanium; \\ Ceramic additives; \\ TiB whisker; \\ Microstructure; \\ Mechanical properties.
}

\begin{abstract}
Monolithic titanium, Ti-1 wt $\% \mathrm{~B}_{4} \mathrm{C}$, and Ti-2.5 wt $\% \mathrm{TiB}_{2}$ were spark plasma sintered at $1050^{\circ} \mathrm{C}$ for 5 min under $50 \mathrm{MPa}$. The effects of $\mathrm{B}_{4} \mathrm{C}$ and $\mathrm{TiB}_{2}$ additions on densification process, microstructural development, and mechanical properties of titanium were investigated. The results revealed that relative density of undoped as well as $\mathrm{B}_{4} \mathrm{C}-$ and $\mathrm{TiB}_{2}$-doped $\mathrm{Ti}$ samples reached $\sim 98-99 \%$. X-ray diffraction patterns, thermodynamic assessments, and microstructural investigations verified the in-situ formation of $\mathrm{TiB}$ whiskers in both composite samples as well as the appearance of $\mathrm{TiC}$ spheres in $\mathrm{Ti}-\mathrm{B}_{4} \mathrm{C}$ composite. However, trace unreacted $\mathrm{TiB}_{2}$ and $\mathrm{B}_{4} \mathrm{C}$ additives remained in the composites as a result of incomplete chemical reactions due to short-time SPS process. Compared to undoped $\mathrm{Ti}$ sample, grain growth was hindered when the sample was doped by $\mathrm{B}_{4} \mathrm{C}$ or $\mathrm{TiB}_{2}$. Elongation, ultimate tensile strength, and Vickers hardness of $\mathrm{B}_{4} \mathrm{C}$ - or $\mathrm{TiB}_{2}$-doped samples were higher than those of monolithic titanium, but bending strength of ceramicdoped samples was significantly lower, compared to undoped titanium. These outcomes were discussed in detail and related to the presence/formation of several ceramic phases with different morphologies in Ti matrix.
\end{abstract}

(C) 2018 Sharif University of Technology. All rights reserved.

\section{Introduction}

Powder Metallurgy (PM) is known as an economical processing method for the densification of ceramicreinforced metal matrix composites, compared to the other techniques such as combustion synthesis, casting or rapid solidification. Spark Plasma Sintering (SPS) is considered as an interesting densification method to fabricate near-fully dense samples quickly at relatively lower temperatures compared to conventional sintering

*. Corresponding authors.

E-mail addresses: abbas.sabahi.64@gmail.com (A. Sabahi Namini);shahedi@uma.ac.ir (M. Shahedi Asl)

doi: $10.24200 /$ sci. 2017.4499 methods, such as Hot Pressing (HP) process. In this method, raw materials are pressed in a graphite die, and a direct current pulse voltage is applied. Plasma generation between the particles can accelerate the mass transfer and diffusion in the materials. The consequent joule effect and plastic deformation lead to the progress of sintering process. Using a short-time densification method can be useful when a fine-grained microstructure is required. SPS process can be used to fabricate metals, ceramics, and composite materials [1-8].

Titanium has a combination of excellent characteristics such as light weight, good strength, and high corrosion resistance; however, its applications have been limited due to low stiffness and wear resistance. To overcome such restrictions, composite 
strategies have been recently developed. Titaniumbased composites have been employed in several applications, such as die casting, military, automotive, aerospace, biomedical industries as well as sporting goods, because of their superior properties, e.g. high strength and excellent wear, corrosion, creep, and fatigue resistances [9-13].

It was reported that the characteristics of $\mathrm{Ti}$ based composites can be improved by adding ceramic particles to the matrix $[14,15]$. Several ceramic additives, such as $\mathrm{Al}_{2} \mathrm{O}_{3}$, TiN, $\mathrm{TiB}_{2}, \mathrm{SiC}, \mathrm{TiC}$, and $\mathrm{B}_{4} \mathrm{C}$, have been added as reinforcement phases to Ti-based composites in order to investigate the influences of such additives on microstructure as well as physical and mechanical properties [16-18]. The most effective approach to improving mechanical properties of a composite is to control the interfaces of matrix and secondary phases. Insufficient chemical bonding between $\mathrm{Ti}$ as the matrix and ceramic reinforcements as the secondary phases leads to weak mechanical properties. Hence, the in-situ formation of reinforcement phases (e.g. TiB whiskers) is a fascinating trick to obtain an excellent interfacial bonding between the matrix and secondary phases [19-23].

The growth of TiB occurs one-dimensionally along the [010] direction, while those of $\mathrm{B}_{4} \mathrm{C}$ or $\mathrm{TiB}_{2}$ are two-dimensional; therefore, generation of a whisker morphology is possible. The in-situ formed TiB whiskers, through chemical reactions between $\mathrm{Ti}$ and additives, have very strong and clean interfaces with $\mathrm{Ti}$ matrix, because there is no intermediate phases between $\mathrm{Ti}$ and $\mathrm{TiB}$. The boron source required to form $\mathrm{TiB}$ can be added in the form of $\mathrm{B}_{4} \mathrm{C}, \mathrm{TiB}_{2}$, or other additives. It was reported that the in-situ formation of TiB whiskers in the spark plasma sintered Ti matrix composites remarkably affects the microstructure and mechanical properties [24-29].

The strengthening mechanisms of particulatereinforced titanium matrix composites have been studied extensively by previous researchers. It seems that the strengthening mechanisms of $\mathrm{Ti}-\mathrm{TiB}_{2}$ system may mainly be attributed to two aspects: direct contributions due to the load transfer from titanium onto $\mathrm{TiB}_{2}$ reinforcements and indirect contributions due to morphological changes of the composite resulting from the in-situ formation of $\mathrm{TiB}$ whiskers, such as grain refinement, solid solution strengthening, geometrically increased density of dislocations, and strengthening due to thermal incompatibilities of the matrix and reinforcements [30-33].

Although several papers have been published on in-situ formed $\mathrm{TiB}_{\mathrm{w}}$ in titanium matrix composites, this research has comparatively investigated the characteristics of $\mathrm{Ti}^{-} \mathrm{TiB}_{\mathrm{w}}$ composites using different ceramic additives as the boron source for $\mathrm{TiB}$ formation. The samples were spark plasma sintered at $1050^{\circ} \mathrm{C}$, with soaking time of $5 \mathrm{~min}$ and applied pressure of $50 \mathrm{MPa}$. Densification, microstructure, and mechanical properties of $\mathrm{B}_{4} \mathrm{C}$ - and $\mathrm{TiB}_{2}$-doped titanium matrix composites were evaluated and compared to monolithic Ti sample.

\section{Experimental procedure}

\subsection{Materials and process}

Commercially available $\mathrm{Ti}$ (particle size $<60 \mu \mathrm{m}$; purity > 98\%; Sigmaaldrich Co.), $\mathrm{B}_{4} \mathrm{C}$ (particle size $<50 \mu \mathrm{m}$; purity > 98\%; Sigmaaldrich Co.), and $\mathrm{TiB}_{2}$ (particle size $\sim 8 \mu \mathrm{m}$; purity $>98 \%$; Xuzhou Hongwu Nanometer Material Co., China) powders were used as raw materials. Scanning electron microscopy micrographs and X-ray diffraction patterns of the as-received starting materials are shown in Figure 1. According to XRD analysis, the identified crystalline phases in Figure 1(a) and (c) are Ti and $\mathrm{TiB}_{2}$, respectively, but Figure $1(\mathrm{~b})$ shows the presence of some remaining carbon in as-received $\mathrm{B}_{4} \mathrm{C}$ powder. The powders were weighed in appropriate ratios to supply monolithic $\mathrm{Ti}$, Ti-1 wt $\% \mathrm{~B}_{4} \mathrm{C}$, and $\mathrm{Ti}-2.5 \mathrm{wt} \%$ $\mathrm{TiB}_{2}$ samples. The contents of the starting materials and the in-situ products were calculated based on the stoichiometry formula. For preparing the composite mixtures, weighed quantities of the as-received powders were mixed thoroughly using a turbula mixer in dry condition at $100 \mathrm{rpm}$ for 5 hours.

The prepared powder mixtures were then uniaxially spark plasma sintered in a SPS furnace (EFSPS-20T-10, with a pulse duration of $3.3 \mathrm{~ms}$ and a current on-off ratio of $12: 2$ ) at $1050^{\circ} \mathrm{C}$ for $5 \mathrm{~min}$ under an external pressure of $50 \mathrm{MPa}$ under vacuum condition $(<1 \mathrm{~Pa})$. The temperature of the die was raised to $1050^{\circ} \mathrm{C}$ with a heating rate of $50^{\circ} \mathrm{C} / \mathrm{min}$ by increasing the direct current, and the pressure was gradually enhanced to $50 \mathrm{MPa}$. The temperature was measured by an infrared pyrometer oriented towards a hole on the external wall of the die directly in line with the sample. For each composition, three disc-shaped samples ( $\sim 50 \mathrm{~mm}$ diameter and $\sim 6 \mathrm{~mm}$ thickness) were fabricated. The powder mixtures were packed into a graphite die, lined with a flexible graphite foil ( $0.5 \mathrm{~mm}$ thickness) as a lubricant to facilitate the extraction of the sintered samples. Finally, the applied current was reduced, external pressure was released, and sintered samples were cooled to the room temperature.

\subsection{Characterization}

Based on datasheets from suppliers, true densities of starting materials were reported to be $4.45,2.43$, and $4.30 \mathrm{~g} / \mathrm{cm}^{3}$ for $\mathrm{Ti}, \mathrm{B}_{4} \mathrm{C}$, and $\mathrm{TiB}_{2}$, respectively. Theoretical densities of spark plasma sintered samples were calculated using the rule of mixtures based on 


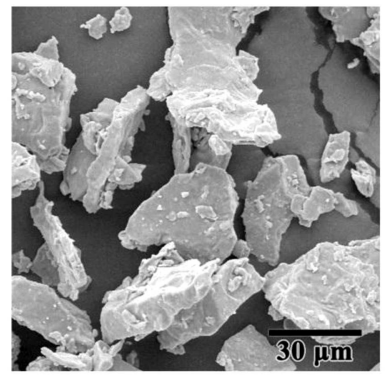

(a)

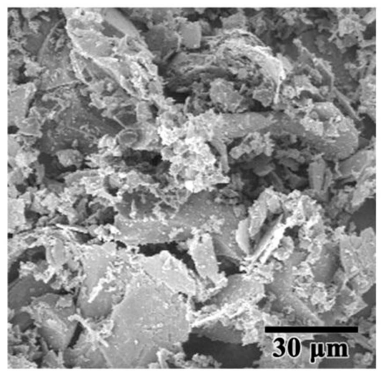

(b)

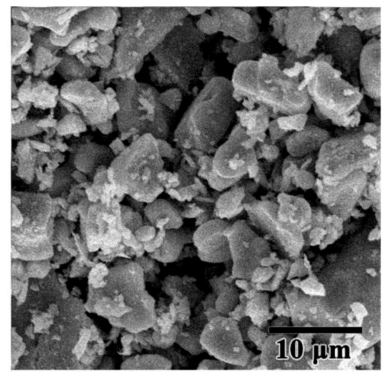

(c)

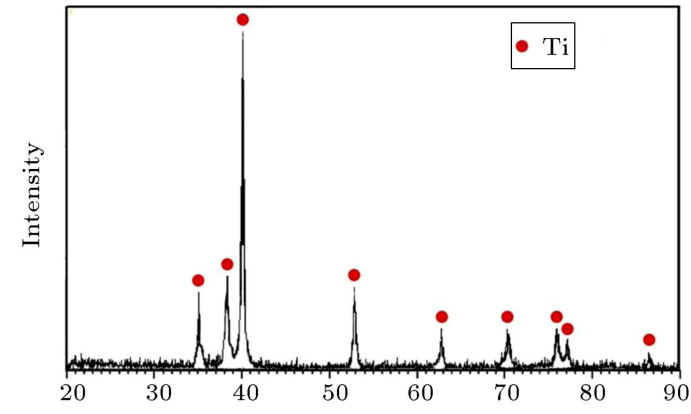

$2 \theta$ (degree)
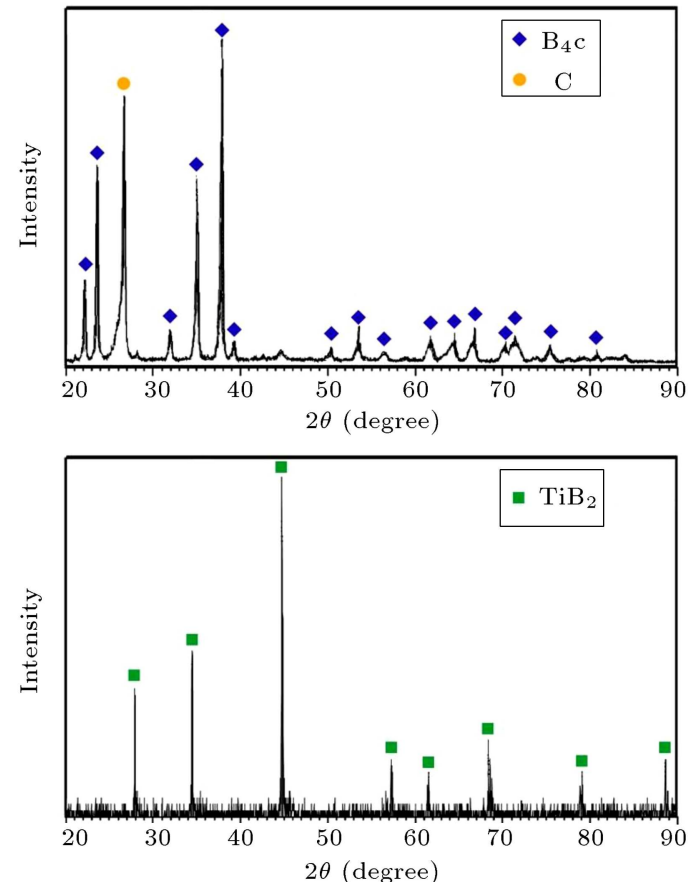

Figure 1. SEM micrographs of morphology and XRD patterns of the as-received: (a) Ti, (b) $\mathrm{B}_{4} \mathrm{C}$, and (c) TiB 2 powders.

the aforementioned values. Bulk densities of the sintered samples were measured by the Archimedes methodology with distilled water as the immersion medium. The conventional procedure of grinding, polishing, and etching by Krolls reagent $(5 \mathrm{ml} \mathrm{HF}$, $10 \mathrm{ml} \mathrm{HNO}_{3}$, and $85 \mathrm{ml} \mathrm{H}_{2} \mathrm{O}$ ) was used for surface preparation. Microstructures of polished and fracture surfaces of the spark plasma sintered samples were investigated using optical (PMG3, Olympus, Japan) and scanning electron (Cam Scan 2300, Czech Republic) microscopes equipped with an energy dispersive spectroscope (DXP-X10P digital X-ray processor). Phase identification of the starting materials and polished assintered samples was performed by X-ray diffraction method (Siemens D5000, Cu lamp, $\lambda=1.54 \AA, 40 \mathrm{kV}$, $30 \mathrm{~mA}$ ). Thermodynamic calculations were performed with HSC Chemistry software (ver. 5.11, Outokumpu Research Oy, Pori, Finland). Microhardness was determined by Vickers' indentation method using a diamond pyramid indenter (Eseway, UK) with a load of $300 \mathrm{~g}$ for $15 \mathrm{~s}$ on the polished surfaces. Each reported hardness value was an average of 10 indentations. Samples were cut to standard dimensions for the evaluation of mechanical properties by Electrical Discharge Machining (EDM) method. Three-point bending strength and room temperature tensile strength were evaluated using a universal testing machine (STM-250) at a constant crosshead speed of $0.5 \mathrm{~mm} / \mathrm{min}$ on the polished specimens. The dimensions of the cut samples for the bending tests were $3 \times 4 \times 3 \times 4 \mathrm{~mm}^{3}$ with a span of $15 \mathrm{~mm}$. Three tests were performed to get an average value of bending strength and to check the reliability of the results. Tensile specimens have gauge dimensions of $2 \times 5 \times 15 \mathrm{~mm}^{3}$, and a total of four specimens were tested for each material.

\section{Results and discussion}

\subsection{Phase identification and chemical reactions}

In order to investigate the phase transformations and chemical reactions during the spark plasma sintering 


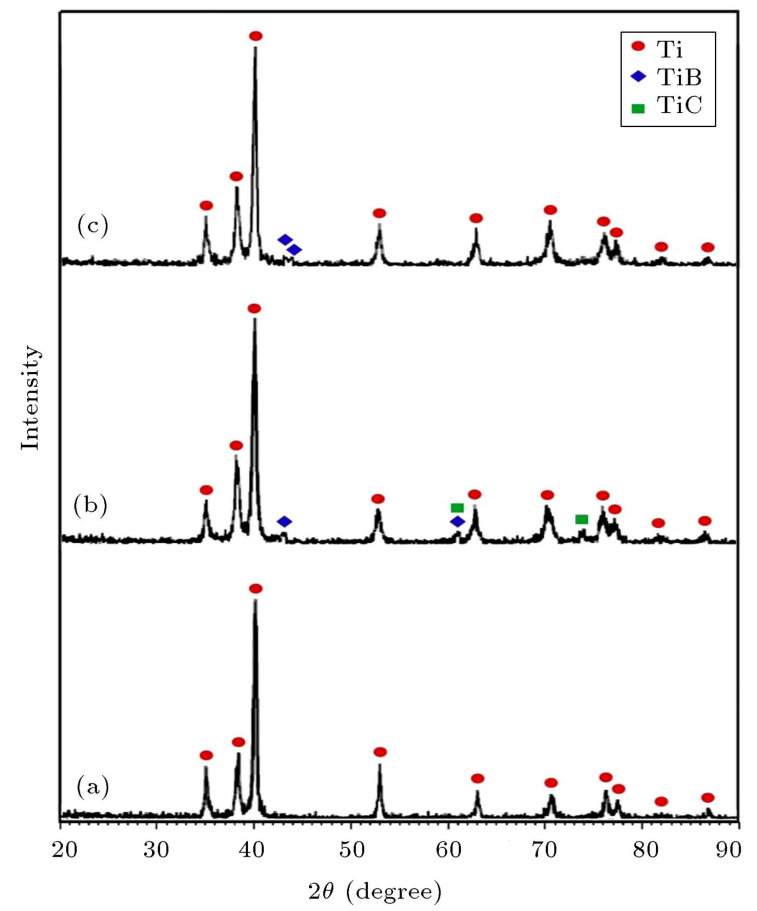

Figure 2. XRD patterns of the spark plasma sintered: (a) monolithic Ti, (b) Ti-1 wt $\% \mathrm{~B}_{4} \mathrm{C}$, and (c) Ti-2.5 wt $\%$ $\mathrm{TiB}_{2}$ samples.

process, X-ray diffraction was performed. The XRD patterns of the sintered monolithic and composite samples are shown in Figure 2. As seen in Figure 2(a), the only detectable phase in the sintered monolithic Ti sample is titanium. This pattern is very similar to the XRD pattern of as-received Ti powder (Figure 1); hence, it seems that no chemical reactions occurred during sintering process of undoped sample.

On the one hand, the XRD pattern of $\mathrm{B}_{4} \mathrm{C}$ doped sample (Figure 2(b)) reveals the presence of $\mathrm{Ti}, \mathrm{TiB}$ and $\mathrm{TiC}$ phases after sintering process. The presence of $\mathrm{TiB}$ and $\mathrm{TiC}$ peaks in this spectrum verifies the in-situ formation of titanium boride and titanium carbide through chemical reactions between $\mathrm{Ti}$ and $\mathrm{B}_{4} \mathrm{C}$ particles. On the other hand, the absence of $\mathrm{B}_{4} \mathrm{C}$ peaks in this pattern suggests that chemical reaction between $\mathrm{Ti}$ and $\mathrm{B}_{4} \mathrm{C}$ has been completed and $\mathrm{B}_{4} \mathrm{C}$ particles have fully reacted during SPS process. However, the presence or absence of trace phases, such as remained $\mathrm{B}_{4} \mathrm{C}$, cannot be proved by XRD analysis, and it requires microstructural investigations, as discussed in Section 3.2.

A relatively similar trend is seen in XRD pattern of $\mathrm{TiB}_{2}$-doped sample (Figure 2(c)). Detection of $\mathrm{Ti}$ and $\mathrm{TiB}$ peaks in this figure confirms the in-situ formation of $\mathrm{TiB}$ due to the reaction between $\mathrm{Ti}$ and $\mathrm{TiB}_{2}$. Similarly, the absence of any detectable $\mathrm{TiB}_{2}$ peak in this spectrum may be the result of completion of chemical reaction between starting materials. Feng et al. [8] reported the same observation for spark plasma sintered $\mathrm{Ti}-\mathrm{TiB}_{2}$ composites at different processing temperatures.

The in-situ formation of $\mathrm{TiB}$ in both $\mathrm{Ti}-\mathrm{B}_{4} \mathrm{C}$ and $\mathrm{Ti}-\mathrm{TiB}_{2}$ composites can be related to the progress of chemical reactions presented in Eq. (1) (extracted from $[27,30]$ and Eq. (2) extracted from [12]). Moreover, as a result of Eq. (2), TiC can be formed along with $\mathrm{TiB}$ in $\mathrm{B}_{4} \mathrm{C}$-doped sample:

$$
\begin{aligned}
& \mathrm{Ti}+\mathrm{TiB}_{2}=2 \mathrm{TiB} \quad[27,30] \\
& 5 \mathrm{Ti}+\mathrm{B}_{4} \mathrm{C}=\mathrm{TiC}+4 \mathrm{TiB} \quad[12]
\end{aligned}
$$

Figure 3 displays the Gibbs free energy and enthalpy values for the chemical reactions (presented by Eqs. (1) and (2) as a function of temperature up to $1050^{\circ} \mathrm{C}$. The Gibbs free energy values of both reactions are negative (Figure 3(a)) in this temperature range, suggesting that both Eqs. (1) and (2) are thermodynamically favorable. In other words, thermodynamic calculations favor the formation of $\mathrm{TiB}$ in both $\mathrm{Ti}-\mathrm{B}_{4} \mathrm{C}$ and $\mathrm{Ti}$ $\mathrm{TiB}_{2}$ composites and formation of $\mathrm{TiC}$ in $\mathrm{B}_{4} \mathrm{C}$-doped sample. In addition, according to the negative values

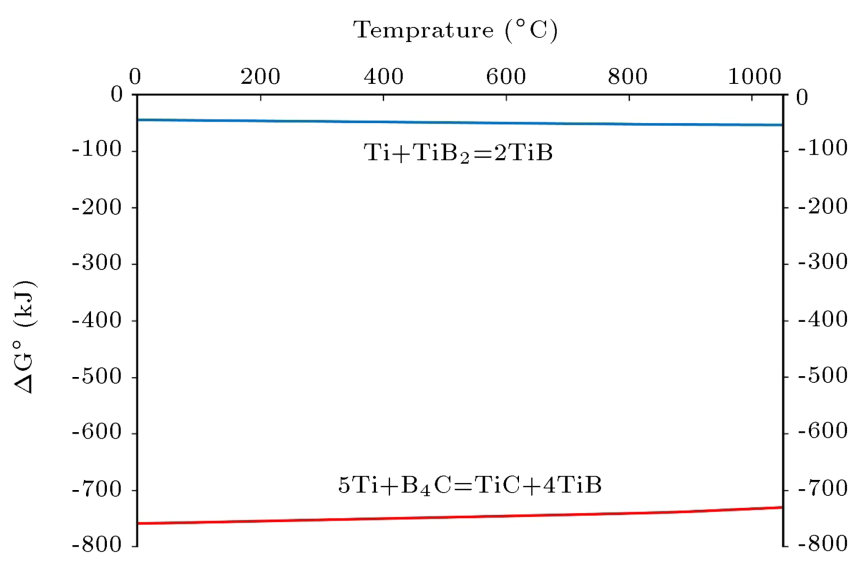

(a)

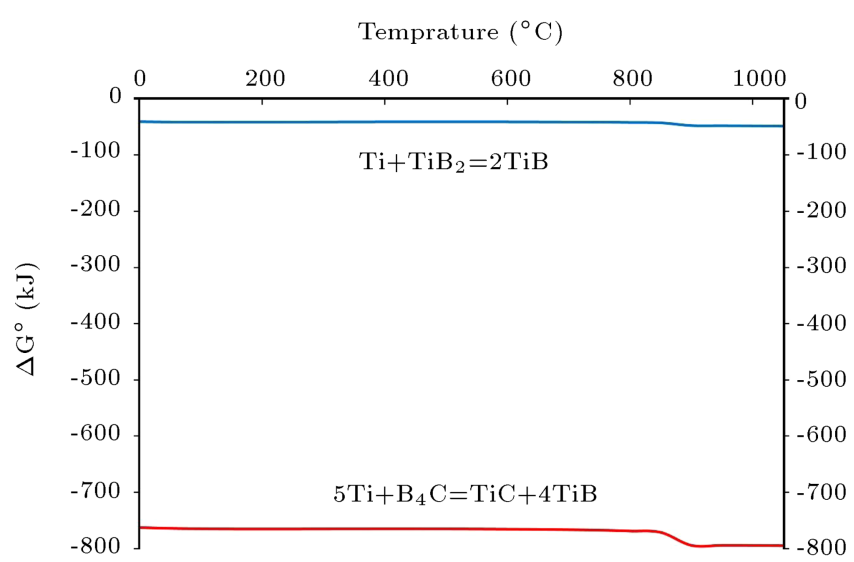

(b)

Figure 3. (a) Gibbs free energy and (b) enthalpy of the chemical reactions based on Eqs. (1) and (2) (calculated by HSC chemistry Software). 
of enthalpy for Eq. (1) and (2) (Figure 3(b)), it can be concluded that the reactions between titanium and ceramic additives $\left(\mathrm{TiB}_{2}\right.$ and $\left.\mathrm{B}_{4} \mathrm{C}\right)$ are exothermic.

\subsection{Microstructural investigations}

Some measured physical and mechanical properties of the spark plasma sintered samples are reported in Table 1. After sintering process, the relative density values of monolithic Ti, Ti- 1 wt $\% \mathrm{~B}_{4} \mathrm{C}$, and Ti-2.5 wt\% $\mathrm{TiB}_{2}$ samples reached $\sim 97.9 \%, \sim 98.5 \%$, and $\sim 98.9 \%$, respectively. It means that less than $\sim 2 \%$ pores remained in the final sintered microstructures, even in undoped Ti sample. However, by incorporating ceramic additives as reinforcement phases in Ti-based composites, the densification process was improved.

The optical and scanning electron microscopy images of the polished and fracture surfaces of assintered monolithic Ti sample are shown in Figures 4-6. As can be clearly seen in Figure 4(a), the monolithic Ti sample has a two-phase microstructure including phases separated by $\beta$ layers. The intergranular beta layers between alpha grains can also be observed in the SEM micrograph of undoped titanium (Figure 4(b)). Since $\mathrm{Ti}$ sample is heated to the sintering temperature of $1050^{\circ} \mathrm{C}$, above the allotropic transformation temperature of titanium at $890^{\circ} \mathrm{C}, \alpha$-Ti converts to $\beta$-Ti during SPS process. However, due to the rapid cooling rate, the reverse transformation could not be completed, and some $\beta$ phase remained at $\alpha$-Ti grain boundaries. The fracture surface of undoped titanium (Figure 4(c)) shows the presence of few porosities $(\sim 2 \%)$; hence, achieving a near-fully dense monolithic Ti sample is possible by the SPS technique. However, a remarkable grain growth occurred in this sample, even at the high heating rate and effective heat transfer in spark plasma sintering process. Based on Figure 4(c), the dominant fracture type of metallic Ti sample, without adding any ceramic particles as the reinforcement phases, is the intergranular quasi-cleavage mode.

Figure 5 displays OM and SEM micrographs of

Table 1. Relative density and mechanical properties of the spark plasma sintered samples.

\begin{tabular}{lccccc}
\hline Sample & $\begin{array}{c}\text { Relative } \\
\text { density (\%) }\end{array}$ & $\begin{array}{c}\text { Elongation } \\
(\mathbf{\%})\end{array}$ & $\begin{array}{c}\text { Ultimate } \\
\text { tensile strength } \\
(\mathbf{M P a})\end{array}$ & $\begin{array}{c}\text { Bending } \\
\text { strength } \\
(\mathbf{M P a})\end{array}$ & $\begin{array}{c}\text { Hardness } \\
\left(\mathbf{H V}_{\mathbf{0 . 3}}\right)\end{array}$ \\
\hline Undoped Ti & $97.9 \pm 0.4$ & $2.68 \pm 0.15$ & $441 \pm 6$ & $2134 \pm 55$ & $305 \pm 15$ \\
$\mathrm{~B}_{4}$ C-doped $\mathrm{Ti}$ & $98.5 \pm 0.5$ & $4.37 \pm 0.22$ & $494 \pm 11$ & $1416 \pm 187$ & $343 \pm 11$ \\
$\mathrm{TiB}_{2}$-doped Ti & $98.9 \pm 0.4$ & $8.67 \pm 0.11$ & $485 \pm 4$ & $1615 \pm 79$ & $363 \pm 8$ \\
\hline
\end{tabular}

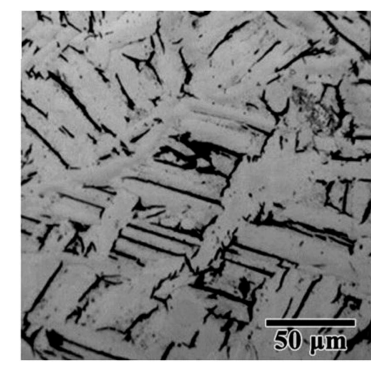

(a)

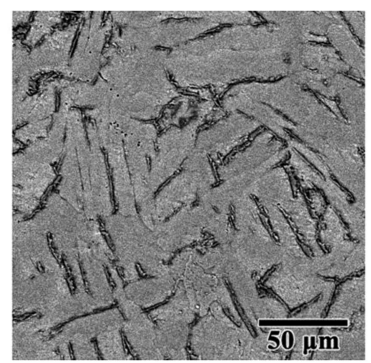

(b)

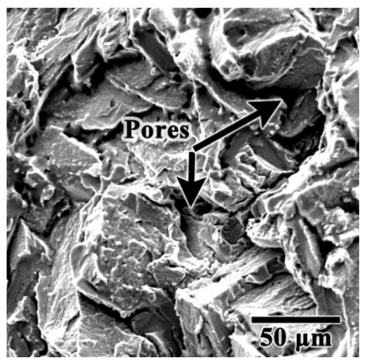

(c)

Figure 4. (a) Optical and (b) scanning electron microscopy images of the polished surface, and (c) SEM micrograph of the fracture surface of monolithic Ti sample.

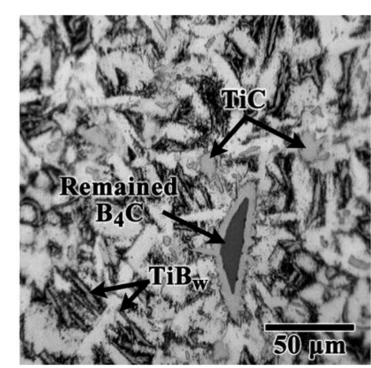

(a)

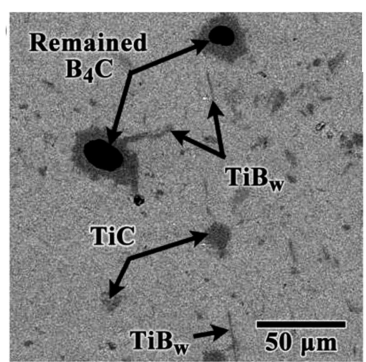

(b)

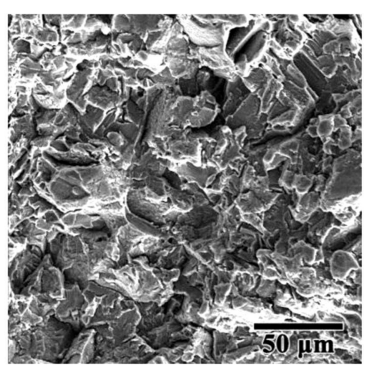

(c)

Figure 5. (a) Optical, and (b) scanning electron microscopy images of the polished surface, and (c) SEM micrograph of the fracture surface of $\mathrm{Ti}-\mathrm{B}_{4} \mathrm{C}$ composite. 


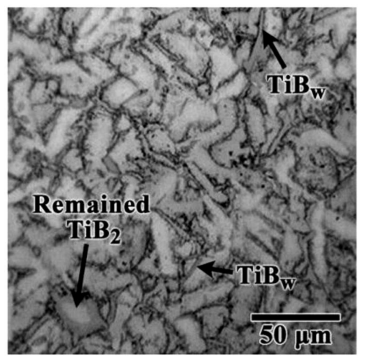

(a)

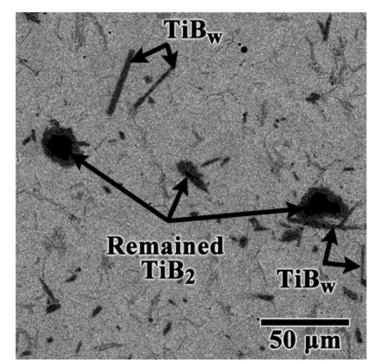

(b)

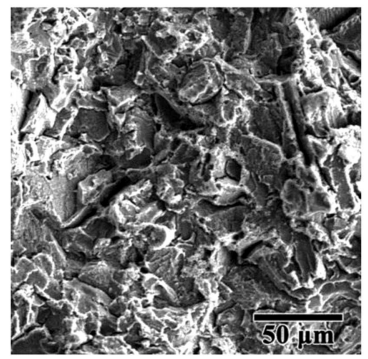

(c)

Figure 6. (a) Optical, and (b) scanning electron microscopy images of the polished surface, and (c) SEM micrograph of the fracture surface of $\mathrm{Ti}^{-} \mathrm{TiB}_{2}$ composite.

the polished and fracture surfaces of $\mathrm{Ti}-1$ wt $\% \mathrm{~B}_{4} \mathrm{C}$ composite. Some fiber-like phases are seen in the polished surfaces of this sample (Figure $5(\mathrm{a})$ and (b)), which can be referred as TiB whiskers.

SEM micrographs (Figure 5(b)) and EDS spectra (not shown here) identified distinct phases: the lightgray phase is Ti matrix, the black one belongs to $\mathrm{B}_{4} \mathrm{C}$, the dark-gray phase with high aspect ratio is in-situ formed TiB, and the spherical dark-gray one is related to in-situ formed TiC. The in-situ formation of such phases was verified by XRD analysis (Figure 2(b)) and thermodynamic calculations approved it (Eq. 2 and Figure 3). Nevertheless, as it can be seen in the polished surfaces, some unreacted $\mathrm{B}_{4} \mathrm{C}$ particles remained in the sintered sample.

The presence of $\mathrm{B}_{4} \mathrm{C}$ particles indicated that the chemical reaction between $\mathrm{Ti}$ and $\mathrm{B}_{4} \mathrm{C}$ (based on $\mathrm{Eq}$. (2)) has not been completed due to kinetic factors. Short holding time of SPS process and/or addition of coarse $\mathrm{B}_{4} \mathrm{C}$ particles are the factors that could slow down the reaction between $\mathrm{Ti}$ and $\mathrm{B}_{4} \mathrm{C}$.

As can be clearly seen in both OM and SEM images, the relatively large-sized remaining $\mathrm{B}_{4} \mathrm{C}$ phases, surrounded by dark-gray coronas, may be a mixture or a solid solution of $\mathrm{TiB}$ and $\mathrm{TiC}$. It seems that finer $\mathrm{B}_{4} \mathrm{C}$ particles completely disappeared and converted to titanium carbides and borides. Moreover, the amount of remained $\mathrm{B}_{4} \mathrm{C}$ phase was not high enough to be detected by XRD. Despite the fact that the amount of in-situ formed $\mathrm{TiB}$ and $\mathrm{TiC}$ is also low, due to the small portion of $\mathrm{B}_{4} \mathrm{C}$ in the starting powder mixture, an effective contact between $\mathrm{Ti}$ and $\mathrm{B}_{4} \mathrm{C}$ particles accelerated the formation and isotropic growth of $\mathrm{TiB}$ as whiskers together with spherical $\mathrm{TiC}$ phases. As it can be seen in Figure 5(b), TiB whiskers initiate from the $\mathrm{Ti} / \mathrm{B}_{4} \mathrm{C}$ interfaces, verifying the formation of $\mathrm{TiB}_{\mathrm{w}}$ as a result of the reaction between $\mathrm{Ti}$ and $\mathrm{B}_{4} \mathrm{C}$ phases (Eq. (2)). The presence of trace $\mathrm{B}_{4} \mathrm{C}$ together with the above-discussed newly formed ceramic phases with different morphologies ( $\mathrm{TiB}$ whiskers and $\mathrm{TiC}$ spheres) affected the fractographical properties of titanium matrix composite. A hybrid brittle and quasi-cleavage fracture mode is seen in Figure 5(c), compared to the undoped $\mathrm{Ti}$ sample with a dominant quasi-cleavage fracture mode (Figure 4(c)).

Figure 6 shows the microstructures of Ti-2.5 wt\% $\mathrm{TiB}_{2}$ composite. Similar to Ti- 1 wt $\% \mathrm{~B}_{4} \mathrm{C}$ sample, the in-situ formed $\mathrm{TiB}$ whiskers are observable in the polished surfaces of this composite. However, unlike $\mathrm{B}_{4} \mathrm{C}$-doped sample, $\mathrm{TiC}$ phases were not formed due to the absence of any carbon sources. Three recognizable regions can be distinguished in SEM micrographs of the polished surface (Figure 6(b)). The light-gray, black and dark-gray phases are $\mathrm{Ti}$ matrix, remained $\mathrm{TiB}_{2}$, and TiB whisker, respectively.

The in-situ formation of $\mathrm{TiB}_{\mathrm{w}}$ was previously confirmed by XRD (Figure 2(c)), and thermodynamic analysis approved it (Eq. (1) and Figure 3). Some unreacted or semi-reacted $\mathrm{TiB}_{2}$ particles also remained in as-sintered microstructure due to the kineticallyinduced limitations of rapid SPS process. It seems that reaction of $\mathrm{Ti}$ matrix with fine $\mathrm{TiB}_{2}$ particles results in in-situ synthesis of TiB whiskers; however, the presence of coarse $\mathrm{TiB}_{2}$ particles leads to the formation of semireacted $\mathrm{TiB}$-surrounded $\mathrm{TiB}_{2}$ structures. TiB whiskers formed through in-situ reactions would bond well with matrix due to the clean interfaces between whiskers and the matrix. The fractographical properties of this sample were also affected by the presence of remained $\mathrm{TiB}_{2}$ particles and in-situ formed TiB whiskers, similar to the $\mathrm{B}_{4} \mathrm{C}$-doped composite. A combined fracture mode of brittle and quasi-cleavage is observed in this sample (Figure 6(c)). Compared to the monolithic Ti sample with a dominant intergranular fracture type, the fracture pattern of $\mathrm{TiB}_{2}$-doped composite is mainly transgranular. Detailed information on brittle and quasi-cleavage fracture modes was reported in other references [34-36].

A schematic illustration of the chemical reactions between the starting materials and microstructural evolution during spark plasma sintering of $\mathrm{B}_{4} \mathrm{C}$ - and $\mathrm{TiB}_{2}$-doped titanium matrix composites is depicted in Figure 7. Before sintering process, $\mathrm{B}_{4} \mathrm{C}$ (coarse and fine) or $\mathrm{TiB}_{2}$ (relatively fine) particles are uniformly located on the surfaces of large $\mathrm{Ti}$ powders. After sintering process, the powder mixtures will be 


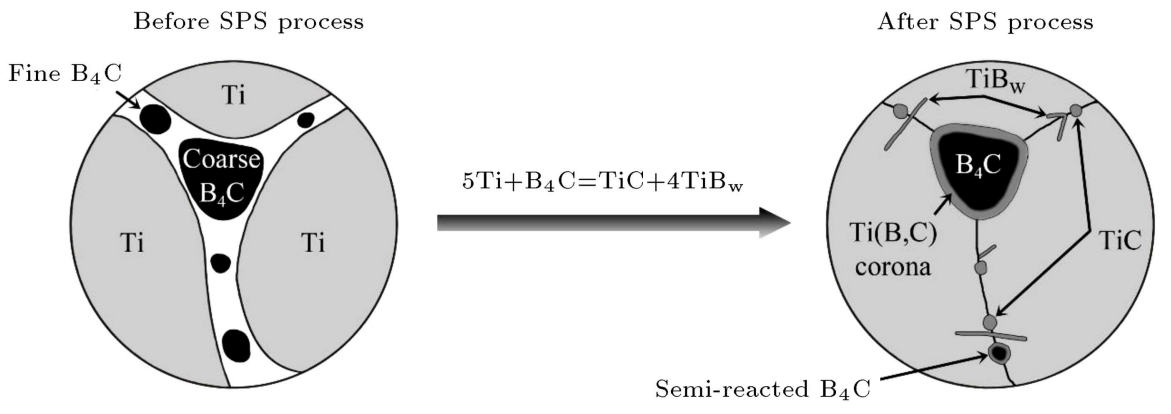

(a)
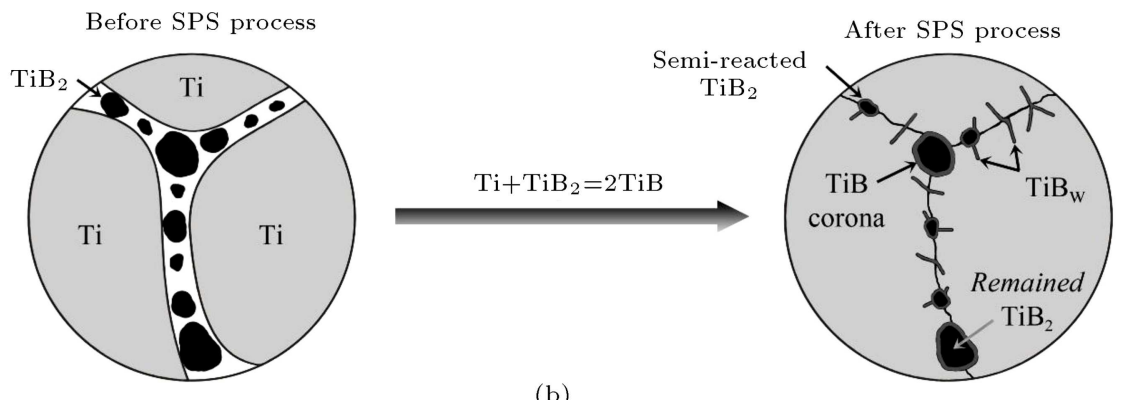

(b)

Figure 7. Schematic exemplification of microstructural evolution during SPS process of (a) Ti-B ${ }_{4} \mathrm{C}$ and (b) Ti-TiB 2 composites.

compacted accompanying neck formation at a high applied pressure of $50 \mathrm{MPa}$ during the SPS process. In addition, the previously discussed calculations and analyses' reactions between titanium and $\mathrm{B}_{4} \mathrm{C}$ or $\mathrm{TiB}_{2}$ will happen at a temperature of $1050^{\circ} \mathrm{C}$. Finally, the growth morphologies of TiB will result in the formation of needle-like $\mathrm{TiB}$ whiskers with a high aspect ratio.

A qualitative comparison of the fracture surfaces (panel c in Figures 4-6) shows that both composite samples have finer $\alpha$-Ti grains than monolithic titanium. It means that the addition of ceramic reinforcements, such as $\mathrm{B}_{4} \mathrm{C}$ and $\mathrm{TiB}_{2}$, influences the grain size of titanium matrix through extra driving force for the nucleation of finer grains, decelerated growth of nuclei as more nuclei can be formed, and the preferred nucleation sites provided by the new interfaces $(\mathrm{Ti} / \mathrm{TiB}$ or $\mathrm{Ti} / \mathrm{TiC})$. In other words, the in-situ formation of $\mathrm{TiB}_{\mathrm{w}}$ in both composite samples, the in-situ formation of $\mathrm{TiC}$ in $\mathrm{B}_{4} \mathrm{C}$-doped sample, and remaining trace additives $\left(\mathrm{B}_{4} \mathrm{C}\right.$ or $\left.\mathrm{TiB}_{2}\right)$ in the sintered samples significantly affect the microstructural evolution of titanium matrix composites via acting as grain growth inhibitors during the sintering process.

\subsection{Mechanical properties}

Some mechanical properties of the spark plasma sintered samples, i.e. hardness, tensile, and bending tests, are reported in Table 1 and plotted in Figure 8 for a better comparison.

The tensile properties (elongation and ultimate tensile strength) of both composite samples are higher than those of the undoped Ti (Figure 8(a) and (b)), which can be related to the combined effects of higher as-sintered density and the presence/formation of several ceramic reinforcement phases with different morphologies. The strengthening of the $\mathrm{B}_{4} \mathrm{C}$ - and $\mathrm{TiB}_{2}$-doped titanium matrix composites not only can be attributed to the transfer of stresses from the metallic matrix to the hard ceramic reinforcements, but also can be related to the morphological variety of secondary phases, which were added to or in-situ formed in the microstructure. Hence, due to the simultaneous effects of higher relative density and a strong interfacial bonding between $\mathrm{Ti} / \mathrm{TiB}_{\mathrm{w}}$, both composite samples showed higher tensile properties than monolithic Ti did. Feng et al. [8] showed that the $\mathrm{TiB}$ reinforcement and the interfacial cohesion between $\mathrm{TiB}$ and Ti matrix are strong enough to undertake the stresses and increase the strength of $\mathrm{TiB}_{\mathrm{w}}$-reinforced titanium matrix composites. However, the higher tensile strength of $\mathrm{B}_{4} \mathrm{C}$-doped sample, compared to $\mathrm{TiB}_{2-}$ doped composite, can be related to in-situ formed $\mathrm{TiC}$ phases besides TiB whiskers. Furthermore, according to the classic Hall-Petch relationship, the fine grain size is beneficial to the room temperature tensile strength. In the current composites, as shown in Figures 5 and 6 , the grain size is significantly refined with incorporating ceramic reinforcements. This means that more grain boundaries exist in the composites due to finer grains, playing an important role in strengthening and improving the tensile strength of the ceramic reinforced specimens. 


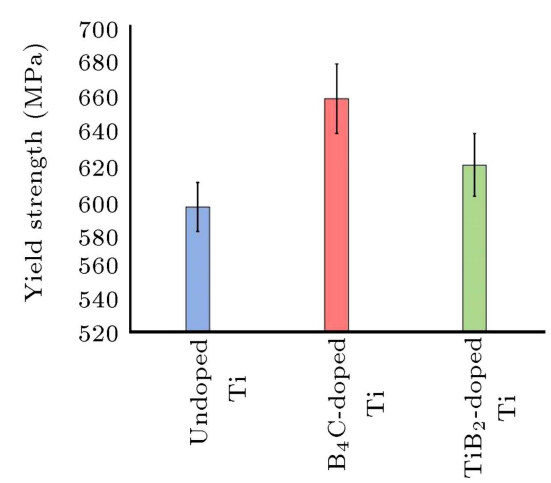

(a)

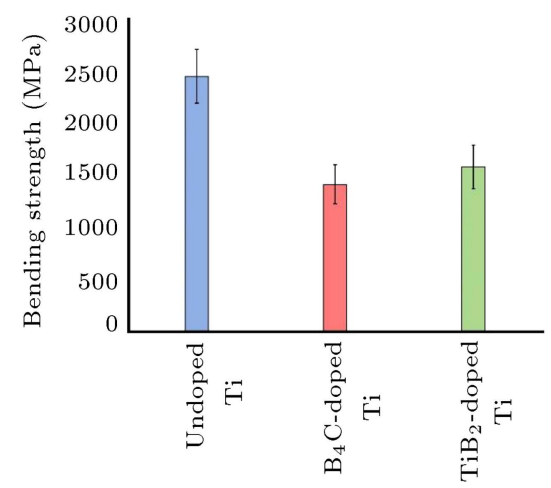

(c)

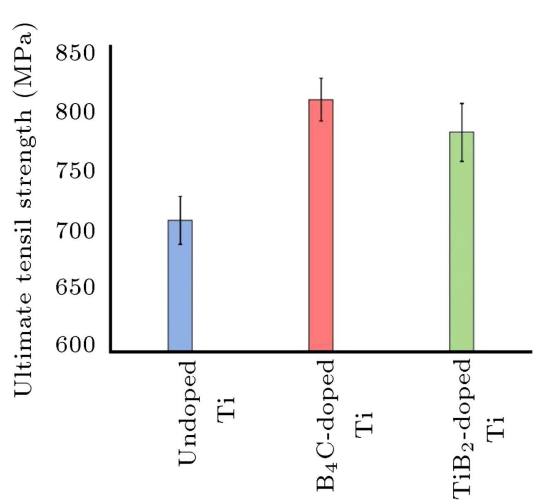

(b)

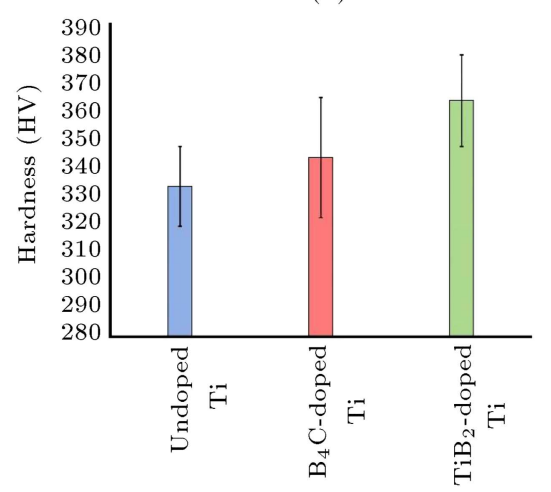

(d)

Figure 8. Mechanical properties of the spark plasma sintered samples: (a) Elongation, (b) ultimate tensile strength, (c) bending strength, and (d) Vickers hardness.

In general, the bending strength of a sample is affected by its relative density and grain size as can be improved with increasing the relative density and decreasing the grain size. Nevertheless, in this research, the monolithic Ti sample showed a higher bending strength than both of the composite samples did (Figure 8(c)). The previously discussed hard phases reduce the bending strength of the composite due to the plastic restraint imposed on the matrix by the in-situ formed $\mathrm{TiB}$ whiskers, $\mathrm{TiC}$ particles, remained $\mathrm{TiB}_{2}$ and $\mathrm{B}_{4} \mathrm{C}$ particles, and subsequent stressing concentration. As the addition of $\mathrm{B}_{4} \mathrm{C}$ to $\mathrm{Ti}$ matrix results in the formation of different hard ceramic phases in assintered microstructure, the $\mathrm{Ti}-\mathrm{B}_{4} \mathrm{C}$ composite has the weakest bending strength in this research work.

Figure 8(d) presents the average hardness values of the titanium matrix in as-sintered samples. The hardness of $\mathrm{Ti}$ matrix is slightly increased by the addition of ceramic particles (such as $\mathrm{B}_{4} \mathrm{C}$ and $\mathrm{TiB}_{2}$ ) as reinforcement phases. The somewhat higher hardness of the composite samples than that of undoped titanium can be related to the higher relative density (lower porosity content) of the ceramic-doped samples. However, it should be noted that some remaining ceramic phases had higher hardness values than that of Ti matrix. For example, the hardness of unreacted $\mathrm{B}_{4} \mathrm{C}$ phases and that of $\mathrm{TiB}$ coronas at $\mathrm{Ti} / \mathrm{B}_{4} \mathrm{C}$ interfaces in $\mathrm{B}_{4} \mathrm{C}$-doped sample were measured $\sim 1500 \mathrm{HV}$ and $\sim 730 \mathrm{HV}$, respectively, compared to the Ti matrix with a lower hardness of $\sim 340 \mathrm{HV}$. As a result, despite the effects of relative density on the hardness increment, it seems that the presence of the remaining unreacted or semi-reacted ceramic reinforcements has predominant effect on hardness rather than density.

\section{Conclusion}

Undoped, $\mathrm{B}_{4} \mathrm{C}$ - and $\mathrm{TiB}_{2}$-doped titanium samples were spark plasma sintered at $1050^{\circ} \mathrm{C}$ for 5 min under a load of $50 \mathrm{MPa}$. The sintered composites contain the in-situ formed phases $\left(\mathrm{TiB}_{\mathrm{W}}\right.$ in $\mathrm{Ti}^{-\mathrm{TiB}_{2}}, \mathrm{TiB}_{\mathrm{W}}+\mathrm{TiC}$ in $\mathrm{Ti}-\mathrm{B}_{4} \mathrm{C}$ ) in titanium matrix, synthesized by chemical reactions between $\mathrm{Ti}$ and additives during the sintering process. Some unreacted or semi-reacted reinforcement particles $\left(\mathrm{TiB}_{2}, \mathrm{~B}_{4} \mathrm{C}\right)$ also remained in as-sintered microstructures due to the kinetic factors. Although high relative densities of $98.5 \%$ and $98.9 \%$ were obtained for $\mathrm{B}_{4} \mathrm{C}$ - and $\mathrm{TiB}_{2}$-doped samples, respectively, the addition of ceramic particles could not significantly affect the sintered density of titanium, compared to undoped sample with a density of $97.9 \%$. However, the presence of the remained ceramic additives, besides insitu formation of some ceramic phases, could hinder the grain growth of titanium matrix. More than $10 \%$ rise 
in the ultimate tensile strength and Vickers hardness values and also $\sim 30 \%$ decrease in bending strength value were found by adding $1 \mathrm{wt} \% \mathrm{~B}_{4} \mathrm{C}$ to titanium. A relatively similar trend was also observed in $\mathrm{TiB}_{2^{-}}$ doped titanium sample.

\section{Acknowledgement}

The authors would like to thank Dr. Mojtaba Yazdani in the Dynamic Behavior of Materials Research Laboratory of Sahand University of Technology for his help on evaluation of mechanical properties.

\section{References}

1. Zhang, Z.H., Liu, Z.F., Lu, J.F., Shen, X.B., Wang, F.C., and Wang, Y.D. "The sintering mechanism in spark plasma sintering - Proof of the occurrence of spark discharge", Scr. Mater., 81, pp. 56-59 (2014).

2. Kumar, M.S., Chandrasekar, P., Chandramohan, P., and Mohanraj, M. "Characterisation of titaniumtitanium boride composites processed by powder metallurgy techniques", Mater. Charact., 73, pp. 43-51 (2012).

3. Borkar, T., Nag, S., Ren, Y., Tiley, J., and Banerjee, R. "Reactive spark plasma sintering (SPS) of nitride reinforced titanium alloy composites", J. Alloys Compd., 617, pp. 933-945 (2014).

4. Ji, L., Chen, B., Li, S.F., Imai, H., Takahashi, M., and Kondoh, K. "Stability of strengthening effect of in situ formed $\mathrm{TiC}_{\mathrm{p}}$ and $\mathrm{TiB}_{\mathrm{w}}$ on the elevated temperature strength of $\left(\mathrm{TiCp}+\mathrm{TiB}_{\mathrm{w}}\right) / \mathrm{Ti}$ composites", J. Alloys Compd., 614, pp. 29-34 (2014).

5. Chaudhari, R. and Bauri, R. "Reaction mechanism, microstructure and properties of $\mathrm{Ti}-\mathrm{TiB}$ in situ composite processed by spark plasma sintering", Mater. Sci. Eng., A, 587, pp. 161-167 (2013).

6. Zhang, Z.H., Shen, X.B., Wen, S., Luo, J., Lee, S.K., and Wang, F.C. "In situ reaction synthesis of Ti-TiB composites containing high volume fraction of $\mathrm{TiB}$ by spark plasma sintering process", J. Alloys Compd., 503, pp. 145-150 (2010).

7. Shen, X., Zhang, Z., Wei, S., Wang, F., and Lee, S. "Microstructures and mechanical properties of the in situ TiB-Ti metal-matrix composites synthesized by spark plasma sintering process", J. Alloys Compd., 509, pp. 7692-7696 (2011).

8. Feng, H., Jia, D., and Zhou, Y. "Spark plasma sintering reaction synthesized $\mathrm{TiB}$ reinforced titanium matrix composites", Composites: Part A, 36, pp. 558563 (2005).

9. Morsi, K., Patel, V.V., Naraghi, S. and Garay, J.E. "Processing of titanium-titanium boride dual matrix composites", J. Mater. Process. Technol., 196, pp. 236-342 (2008).

10. Feng, H.B., Zhou, Y., Jia, D.C., and Meng, Q.C. "Microstructure and mechanical properties of in situ
TiB reinforced Titanium matrix composites based on Ti-FeMo-B prepared by spark plasma sintering", Compos. Sci. Technol., 64, pp. 2495-2500 (2004).

11. Zhang, C., Kong, F., Xiao, S., Niu, H., Xu, L., and Chen, Y. "Evolution of microstructural characteristic and tensile properties during preparation of $\mathrm{TiB} / \mathrm{Ti}$ composite sheet", Mater. Des., 36, pp. 505-510 (2012).

12. Tjong, S.C. and Mai, Y.W. "Processing-structureproperty aspects of particulate- and whisker-reinforced titanium matrix composites", Compos. Sci. Technol., 68, pp. 560-583 (2008).

13. Morsi, K. and Patel, V.V. "Processing and properties of titanium-titanium boride $\left(\mathrm{TiB}_{\mathrm{w}}\right)$ matrix composites-a review", J. Mater. Sci., 42, pp. 20372047 (2007).

14. Wang, M.M., Lu, W.J., Qin, J.N., Ma, F.C., Lu, J.Q., and Zhang, D. "Effect of volume fraction of reinforcement on room temperature tensile property of in situ (TiB+TiC)/Ti matrix composites", Mater. Des., 27, pp. 494-498 (2006).

15. Huang, L.J., Geng, L., Li, A.B., Yang, F.Y., and Peng, H.X. "In situ $\mathrm{TiB}_{\mathrm{w}} / \mathrm{Ti}-6 \mathrm{Al}-4 \mathrm{~V}$ composites with novel reinforcement architecture fabricated by reaction hot pressing", Scr. Mater., 60, pp. 996-999 (2009).

16. Boehlert, C.J., Tamirisakandala, S., Curtin, W.A., and Miracle, D.B. "Assessment of in situ TiB whisker tensile strength and optimization of TiB-reinforced titanium alloy", Scr. Mater., 61, pp. 245-248 (2009).

17. Sung, S.Y., Choi, B.J., and Kim, Y.J. "Evaluation the properties of titanium matrix composites by melting route synthesis", J. Mater. Sci. Technol, 24, pp. 105109 (2008).

18. Abkowitz, S., Abkowitz, S.M., Fisher, H., and Schwartz, P.J. "CermeTi discontinuously reinforced Ti-matrix composites: manufacturing, properties, and applications", JOM, 56, pp. 37-41 (2004).

19. Tjong, S.C. and Ma, Z.Y. "Microstructural and mechanical characteristics of in situ metal matrix composites", Mater. Sci. Eng., R, 29, pp. 49-113 (2000).

20. Shufeng, L.I., Kondoh, K., Imai, H., Chen, B., Jia, L., and Umeda, J. "Microstructure and mechanical properties of $\mathrm{P} / \mathrm{M}$ titanium matrix composites reinforced by in-situ synthesized TiC-TiB", Mater. Sci. Eng., A, 628, pp. 75-83 (2015).

21. Wei, S., Zhang, Z.H., Wang, F.C., Shen, X.B., Cai, H.N., Lee, S.K., and Wang, L. "Effect of Ti content and sintering temperature on the microstructures and mechanical properties of TiB reinforced titanium composites synthesized by SPS process", Mater. Sci. Eng., A, 560, pp. 249-255 (2013).

22. Tabrizi, S.G., Sajjadi, S.A., Babakhani, A., and Lu, W. "Influence of spark plasma sintering and subsequent hot rolling on microstructure and flexural behavior of in-situ TiB and TiC reinforced Ti6Al4V composite", Mater. Sci. Eng., A, 624, pp. 271-278 (2015). 
23. Zhang, C.J., Kong, F.T., Xiao, S.L., Zhao, E.T., Xu, L.J., and Chen, Y.Y. "Evolution of microstructure and tensile properties of in situ titanium matrix composites with volume fraction of $(\mathrm{TiB}+\mathrm{TiC})$ reinforcements", Mater. Sci. Eng., A, 548, pp. 152-160 (2012).

24. Shen, X., Zhang, Z., Wei, S., Wang, F., and Lee, S. "Microstructures and mechanical properties of the in situ TiB-Ti metal-matrix composites synthesized by spark plasma sintering process", J. Alloys Compd., 509, pp. 7692-7696 (2011).

25. Patel, V.V., El-Desouky, A., Garay, J.E., and Morsi, K. "Pressure-less and current-activated pressureassisted sintering of titanium dual matrix composites: Effect of reinforcement particle size", Mater. Sci. Eng., A, 507, pp. 161-166 (2009).

26. Zhang, C.J., Kong, F.T., Xu, L.J., Zhao, E.T., Xiao, S.L., Chen, Y.Y., Deng, N.J., Geb, W., and Xu, G.J. "Temperature dependence of tensile properties and fracture behavior of as rolled TiB/Ti composite sheet", Mater. Sci. Eng., A, 556, pp. 962-969 (2012).

27. Yan, Z., Chen, F., Cai, Y., and Zheng, Y. "Microstructure and mechanical properties of in-situ synthesized TiB whiskers reinforced titanium matrix composites by high-velocity compaction", Powder Technol., 267, pp. 309-314 (2014).

28. Shahedi Asl, M., Sabahi Namini, A., and Ghassemi Kakroudi, M. "Influence of silicon carbide reinforcement on the microstructural development of hot pressed zirconium and titanium diborides", Ceram. Int., 42, pp. 5375-5381 (2016).

29. Sabahi Namini, A., Seyed Gogani, S.N., Shahedi Asl, M., Farhadi, K., Ghassemi Kakroudi, M., and Mohammadzadeh, A. "Microstructural development and mechanical properties of hot pressed $\mathrm{SiC}$ reinforced $\mathrm{TiB}_{2}$ based composite", Int. J. Refract. Met. Hard Mater., 51, pp. 169-179 (2015).

30. Huang, L.J., Geng, L., Peng, H.X., Balasubramaniam, K., and Wang, G.S. "Effects of sintering parameters on the microstructure and tensile properties of in situ $\mathrm{TiB}_{\mathrm{w}} / \mathrm{Ti} 6 \mathrm{Al} 4 \mathrm{~V}$ composites with a novel network architecture", Mater. Des., 32, pp. 3347-3353 (2011).

31. Huang, L.J., Geng, L., Wang, B., and Wu, L.Z. "Effects of volume fraction on the microstructure and tensile properties of in situ $\mathrm{TiB}_{\mathrm{w}} / \mathrm{Ti} 6 \mathrm{Al} 4 \mathrm{~V}$ composites with novel network microstructure", Mater. Des., 45, pp. 532-538 (2013).
32. Huang, L.J., Geng, L., Peng, H.X., and Zhang, J. "Room temperature tensile fracture characteristics of in situ $\mathrm{TiB}_{\mathrm{w}} / \mathrm{Ti} 6 \mathrm{Al} 4 \mathrm{~V}$ composites with a quasicontinuous network architecture", Scr. Mater., 64, pp. 844-847 (2011).

33. Huang, L.J., Geng, L., Wang, B., Xu, H.Y., and Kaveendran, B. "Effects of extrusion and heat treatment on the microstructure and tensile properties of in situ $\mathrm{TiB}_{\mathrm{w}} / \mathrm{Ti} 6 \mathrm{Al} 4 \mathrm{~V}$ composite with a network architecture", Composites Part A, 43, pp. 486-491 (2012).

34. Zhang, C.J., Kong, F.T., Xiao, S.L., Zhao, E.T., Xu, L.J., and Chen, Y.Y. "Evolution of microstructure and tensile properties of in situ titanium matrix composites with volume fraction of $(\mathrm{TiB}+\mathrm{TiC})$ reinforcements", Mater. Sci. Eng., A, 548, pp. 152- 160 (2012).

35. Wei, S., Zhang, Z.H., Wang, F.C., Shen, X.B., Cai, H.N., Lee, S.K., and Wang, L. "Effect of Ti content and sintering temperature on the microstructures and mechanical properties of TiB reinforced titanium composites synthesized by SPS process", Mater. Sci. Eng., A, 560, pp. 249-255 (2013).

36. Li, B.S., Shang, J.L., Guo, J.J., and Fu, H.Z. "In situ observation of fracture behavior of in situ $\mathrm{TiB}_{\mathrm{w}} / \mathrm{Ti}$ composites", Mater. Sci. Eng., A, 383, pp. 316-322 (2004).

\section{Biographies}

Abbas Sabahi Namini is currently a PhD student at the Department of Materials Engineering, Sahand University of Technology, Tabriz, Iran. His research interests include liquid phase sintering, powder metallurgy, and composite materials.

Maziyar Azadbeh, PhD, is currently an Associate Professor at the Department of Materials Engineering, Sahand University of Technology, Tabriz, Iran. His research interests include powder metallurgy, aluminum recycling, and surface engineering.

Mehdi Shahedi Asl, PhD, is currently an Assistant Professor at the Department of Mechanical Engineering, University of Mohaghegh Ardabili, Ardabil, Iran. His research interests include metal and ceramic matrix composites, sintering processes, and nano materials. 